\title{
Evaluation the Growth Performance of Egyptian Garlic Landraces and In vitro Synseeds of Bulblets Formation
}

\author{
Hegazy H. hegazy ${ }^{1}$, Gehan A. Elsharkawy ${ }^{1}$ and Salat elnabe S. ahmad ${ }^{2}$ \\ ${ }^{1}$ Vegetable crops department faculty of agriculture Alexandria University \\ ${ }^{2}$ City of Scientific Research and Technological Applications (SRTA-City), New Borg El-Arab, Egypt
}

\begin{abstract}
Egyptian garlic cultivars suffered degenerations; lower bulb yield and smaller size of bulbs which represent a crucial problem. A survey of some Egyptian landraces to detect there genetic diversity is considered in this study . In addition, developing of simple method for bulblets regeneration and synthetic seed formation to decrease amount of clove seeds. Fourteen vegetative growth and bulb characteristics for 27 Egyptian garlic landraces were measured during two growing season to determine the phenotypic variations under condition of New Borg El-Arab, Egypt. An in vitro study was, also, carried out to determine the direct shoot induction and bulblets formation for six selected landraces and under three media protocol. The results of the field experiment revealed that, Significant differences among all studied local cultivars and ecotypes of Egyptian garlic were observed for vegetative growth, bulb and total yield characteristics . Among the studied varieties of Egyptian landraces, Borg El-Arab landrace was superior in vegetative growth as plant height (cm), leaves no./ plant, leaf length $(\mathrm{cm})$, leaf width $(\mathrm{mm})$, plant fresh weight $(\mathrm{g})$ and foliage fresh weight $(\mathrm{g})$. While, quality characters were associated with purple bulbs landraces like Egaseed and Sids-40-Ayat. Bulb dry matter percentage ranged from 36.6 to $45.68 \%$ and from 35.07 to $44.89 \%$ however, average cloves number per bulb was ranged from 9.33 to 40.00 and from 3.55 to 32.71 in the first and second growing seasons, respectively. The results for the invitro experiment revealed that efficient and simple method of bulblets regeneration and improving multiplication rate were developed for six selected landraces using three different media. Garlic explants (cultured on MS media) were supplemented with $6 \%$ sucrose and 2 mg/l JA (T-3); produced significant higher mean values for numbers of bulblets /clove (12.61) and higher insignificant mean values for numbers of shoots and bulblets /explant, bulblets formation \% and numbers of bulblets per clove compared with control treatment (T-1). Control treatment (T-1) produced the highest significant average bulblet weight $(259.72 \mathrm{mg})$. "Salaqus-3" landrace was superior and gave the highest significant mean values for number of shoots per explant and bulblets per clove compared with other landraces. "Clone-21" produced the highest bulblet weight (232.94 $\mathrm{mg}$ ). Synthetic seeds for six garlic landraces formed by immersing bulblets in gel matrix (3\% sodium alginate solution), and exposure to calcium chloride solution $(2.5 \%)$ were germinated successfully in unsterilized soil mixture consisted of peatmoss, sand and soil (1:1:1). Conclusion: Egyptian garlic landraces showed great variability and a promising in vitro performance for plant regeneration and bulblets formation. This finding could be used as alternative propagation method, cultivars rejuvenation and germplasm conversation management along with capsulation technology.
\end{abstract}

Key wards: garlic Landraces - bulblets formation - Jasmonic acid (JA)- Synthetic seeds- capsulation.

\section{INTRODUCTION}

Due to the importance of garlic as vegetable and medicinal plant for various parts of the worlds, it become necessity to protect garlic plants from extinction and bullbats against various crop diseases in addition to maintain high quality selection procedure for used bullbats for future planting. The present study investigates the effect of environmental conditions on the various vegetation characters. Also, it explore an in vitro technique to improve the efficiency and simplify the method for direct shoot and bulblets regeneration and synthetic seed formation. Such approach enhance cultivars ability to select best bulbelts for future use, and achieve higher yield products.

Garlic, (Allium sativum L.) belongs to the Alliaceae family and genus Allium, which has approximately 450 species, (Lanzotti, 2006). Garlic is considered the second most important Allium species and vegetable after onion. It is used as flavoring agent for cooking and medicinal plant in many cultures for thousands of years. Vavilov, (1926) reported that Central Asia is the primary center of garlic. Moreover, the Mediterranean region has been postulated as the secondary center of garlic diversity, (vavilov, 1951). Egypt is considered the fourth country of the world's output of garlic. The cultivated area of garlic in Egypt reached 9,674 ha in 2010 yielding 244,626 tons with an average of 25.29 ton/ha, (FAO, 2016). Egyptian garlic cultivars suffered degenerations; lower bulb yield and smaller size of bulbs. The reported reasons for such phenomenon are shortage of attention for selection and breeding during cultivation practices, which lead to populations mix up, and the sale of highquality garlic which left only the low-quality ones for next year production (Abdel-halim, 2014). Furthermore, the infection by endless viruses and occurrence of secondary growth aggravated the situation. Whereas, garlic is often infected by multiple viruses that belong to different taxa and are collectively designated as the 'garlic viral complex'. These viruses may not kill the plant but can reduce yield up to $70 \%$ over time (Conci et al., 2003; Nagakubo et al. 1993; 1997). 
Wide range of morphological variations has been observed in garlic and was responding to both environment and plant maturity; including flowering ability and bulbing (Senula and Keller, 2000). Moreover, landrace response to environmental variations is considered of high importance to breeder and producer.

Vegetative mode of multiplication -used for garlic propagation- facilitates disease transfer and limits breeding efforts due to the slow screening and selection of spontaneous or induced mutations. Micropropagation through in-vitro bulblets formation has been used as a reliable and excellent alternative to pathogen free plantlets and cultivars regeneration. Therefore, synthetic seed technology is a highly promising tool for the management of tissue culture products and seedless plant species. It provides additional protection for tissue culture products (Sharma et al., 2013).

The objectives of this study are evaluation the performance of some Egyptian garlic landraces (Allium sativum L.) to detect there genetic diversity, and invitro improving efficient and simple method for direct shoot and bulblets regeneration and synthetic seed formation.

\section{MATERIALS AND METHODS}

The present study consisted of two experiments; the first one aimed to study the performance of 27 Egyptian landraces of garlic under the field conditions. While, the second experiment aimed to measure the performance of six selected Egyptian garlic landraces under in vitro condition for shoot and bulblets formation and synthetic seeds (synseeds) production.

\section{1-Field experiments}

A field experiments were conducted during two different growing seasons winter seasons of 2015 and 2016 at the experimental farm of the City of Scientific Research and Technological Applications (SRTA-City), New Borg El-Arab, Egypt (Approx. latitude is $30^{\circ} 53^{\prime} 36.52^{\prime \prime} \mathrm{N}$ and longitude $\left.29^{\circ} 32^{\prime} 48.27^{\prime \prime} \mathrm{E}\right)$ to evaluate the morphological and bulb characteristics of 27 garlic landraces collected from different regions in Egypt as shown in (Table 1).

Table 1: Bulb characteristics and regions of the 27 landraces of Egyptian garlic.

\begin{tabular}{|c|c|c|c|}
\hline Landrace & $\begin{array}{c}\text { skin Bulb } \\
\text { color }\end{array}$ & $\begin{array}{c}\text { Clove } \\
\text { Characteristics } \\
\end{array}$ & Region \\
\hline Balady & \multirow{16}{*}{ white } & \multirow{16}{*}{$\begin{array}{l}\text { arranged from } 20 \text { Small size, } \\
\text { organized on tto } 45 \text { per bulb } \\
\text { more than five groups }\end{array}$} & El- Minia governorate \\
\hline Balady- Al Wadi & & & El-WadiEl-Gadid governorate \\
\hline Clone-1 & & & El- Minia governorate \\
\hline Clone-5 & & & El- Minia governorate \\
\hline Clone-18 & & & El- Minia governorate \\
\hline Clone-22-W & & & El- Minia governorate \\
\hline Clone-24 & & & El- Minia governorate \\
\hline Clone-25 & & & El- Minia governorate \\
\hline El Ewinat & & & El-WadiEl-Gadid governorate \\
\hline Farmer's clone & & & El- Minia governorate \\
\hline Salaqus-3 & & & Bani Swaife governorate \\
\hline Aswan & & & Aswan governorate \\
\hline Borg El-Arab & & & Alexandria governorate \\
\hline El Behera & & & El Behera governorate \\
\hline El Fayoum-1 & & & El Fayoum governorate \\
\hline E1 Fayoum-2 & & & El Fayoum governorate \\
\hline Egaseed-1A & \multirow{11}{*}{ purple } & \multirow{8}{*}{$\begin{array}{c}\text { Medium size, arranged from } \\
\text { organized on } 3 \text { or } 413 \text { to } 20 \text {, } \\
\text { groups }\end{array}$} & Egaseed company \\
\hline Egaseed-1B & & & Egaseed company \\
\hline Egaseed-2 & & & Egaseed company \\
\hline Egaseed-3 & & & Egaseed company \\
\hline Salaqus & & & Bani Swaife governorate \\
\hline Clone-21 & & & El- Minia governorate \\
\hline Clone-22-R & & & El- Minia governorate \\
\hline Al Ayat-1 & & & El- Giza governorate \\
\hline Bany gonamy & & \multirow{3}{*}{$\begin{array}{l}\text { Large size, arranged from } 8 \text { to } \\
13 \text {, organized on } 1 \text { or } 2 \text { groups }\end{array}$} & Bani Swaife governorate \\
\hline Sids-40-R.S. & & & Bani Swaife governorate \\
\hline Sids-40-Ayat & & & El- Giza governorate \\
\hline
\end{tabular}


Cloves of the 27 garlic landraces were sown in $8^{\text {th }}$ of September during both growing seasons. Seeds were planted at $10 \mathrm{~cm}$ distance apart within the row. Each experimental unit consisted of 2 rows, $4 \mathrm{~m}$ long and $50 \mathrm{~cm}$ width, occupying an area of 4 $\mathrm{m}^{2}$. The experimental layout used was Randomized Complete Block Design (RCBD) with three replicates. The data were statistically analyzed by ANOVA Percentage data were normalized using costat software and means between landraces were compared by using revised LSD test with $5 \%$ level of probability as described by Snedecor and Cochran (1980).

Soil samples of the experimental sites were taken for the determination of soil physical and chemical properties. Soil Physical and chemical properties of the two experimental sites indicated sandy clay loam texture with $\mathrm{pH}$ ranged from 8.34 to 8.30 respectively. Organic matter content ranged from 0.98 and $0.93 \%$ (Table 2)

Data of maximum and minimum temperatures for both growth seasons were cited and are shown in Table (3).

Table 2: The physical and chemical properties of the two experimental soil sites in the two seasons of 2015/2016 and 2016/2017.

\begin{tabular}{|c|c|c|}
\hline \multirow{2}{*}{ Soil parameter* } & \multicolumn{2}{|c|}{ Values } \\
\hline & $2015 / 2016$ & 2016/2017 \\
\hline $\mathrm{pH}(1: 2.5 \mathrm{w}: \mathrm{w})$ & 8.34 & 8.30 \\
\hline Electrical conductivity $(\mathrm{EC})(\mathrm{dS} / \mathrm{m}, 1: 1 \mathrm{w}: \mathrm{w})$ & 1.74 & 2.45 \\
\hline Total N (\%) & 0.03 & 0.02 \\
\hline Available P (mg/kg) & 4.20 & 5.01 \\
\hline Available K (mg/kg) & 320.2 & 332.28 \\
\hline Total $\mathrm{CaCO} 3(\%)$ & 30.6 & 31.05 \\
\hline $\mathrm{CEC}(\mathrm{Cmol}+/ \mathrm{kg})$ & 11.81 & 10.11 \\
\hline Organic Matter (\%) & 0.98 & 0.93 \\
\hline Organic C $(\%)$ & 0.56 & 0.49 \\
\hline Total DOC (\%) & 0.012 & 0.010 \\
\hline Sand $(\%)$ & 64.1 & 62.7 \\
\hline Silt (\%) & 15.2 & 17.4 \\
\hline Clay $(\%)$ & 20.7 & 19.9 \\
\hline Texture & Sandy Clay Loam & Sandy Clay Loam \\
\hline \multicolumn{3}{|l|}{ Soluble ions (mg/kg, 1:1w:w) } \\
\hline $\mathrm{Ca} 2+$ & 162.4 & 182.12 \\
\hline $\operatorname{Mg} 2+$ & 61.32 & 66.10 \\
\hline $\mathrm{Na}+$ & 52.90 & 60.52 \\
\hline $\mathrm{K}+$ & 71.76 & 75.14 \\
\hline CO32- & 0.00 & 0.00 \\
\hline HCO3- & 381.2 & 389.11 \\
\hline $\mathrm{SO} 4-$ & 274 & 281.10 \\
\hline \multicolumn{3}{|l|}{ Micronutrients $(\mathrm{mg} / \mathrm{kg})$} \\
\hline $\mathrm{Fe} 2+$ & 4.10 & 4.15 \\
\hline $\mathrm{Zn} 2+$ & 1.43 & 1.44 \\
\hline $\mathrm{Mn} 2+$ & 3.49 & 3.71 \\
\hline $\mathrm{Cu} 2+$ & 0.61 & 0.65 \\
\hline $\mathrm{B}+$ & 0.30 & 0.32 \\
\hline $\mathrm{Cl}-$ & 192 & 200 \\
\hline
\end{tabular}

Table 3: Average minimum and maximum temperatures $\left({ }^{\circ} \mathrm{C}\right)$ every two-weeks during the experimental time of 2015/2016 and 2016/2017, respectively.

\begin{tabular}{|c|c|c|c|c|c|c|c|c|c|c|c|c|c|c|c|}
\hline \multicolumn{16}{|c|}{$2015 / 2016$} \\
\hline \multirow{2}{*}{ Date } & \multicolumn{2}{|c|}{ September } & \multicolumn{2}{|c|}{ October } & \multicolumn{2}{|c|}{ November } & \multicolumn{2}{|c|}{ December } & \multicolumn{2}{|c|}{ January } & \multicolumn{2}{|c|}{ February } & \multicolumn{2}{|c|}{ March } & \multirow{2}{*}{$\frac{\text { April }}{1-15}$} \\
\hline & $1-15$ & $16-30$ & $1-15$ & $16-30$ & $1-15$ & $16-30$ & $1-15$ & $16-30$ & $1-15$ & $16-30$ & $1-15$ & $16-30$ & $1-15$ & $16-30$ & \\
\hline \multicolumn{16}{|c|}{ 2016-2017 } \\
\hline Date & \multicolumn{2}{|c|}{ September } & \multicolumn{2}{|c|}{ October } & \multicolumn{2}{|c|}{ November } & \multicolumn{2}{|c|}{ December } & \multicolumn{2}{|c|}{ January } & \multicolumn{2}{|c|}{ February } & \multicolumn{2}{|c|}{ March } & April \\
\hline Temp. ${ }^{0} \mathrm{C}$ & $23-29$ & $22-28$ & $22-27$ & $20-25$ & $18-22$ & $17-22$ & $14-18$ & $10-15$ & $7-15$ & $10-17$ & $9-18$ & $10-19$ & $12-21$ & $12-21$ & $12-22$ \\
\hline
\end{tabular}

www.wunderground.comSource; 
The data were recorded at maximum growth stage and before harvesting (192 days from planting). Ten randomly selected plants from each experimental unit were chosen for determination of the following characters;

\section{1. Vegetative growth characters:}

Average plant height $(\mathrm{cm})$; number of leaves per plant, plant fresh weight $(\mathrm{g})$ and foliage dry matter percentage were measured. Dry matter content was calculated after drying the plant vegetative growth without bulb at $70^{\circ} \mathrm{C}$.

\section{2. Bulb characteristics:}

Average bulb diameter, bulb dry matter percentage, number of cloves per bulb and average clove weight (g) were assessed. Dry matter content $=($ dry weight $/$ fresh weight $) \times 100$.

\section{Laboratory invitro experiments}

Direct shoot induction, bulblets formation and synseeds productions, were carried out for six selected landraces 'Salaqus-3', 'Aswan', 'Borg ElArab', 'El Behera', 'Sids-40-Ayat' and 'Clone-21' which are taken into consideration after initial screening of the 27 garlic cultivars and ecotypes for in vitro direct shoot induction. The experiments reported herein were carried out during the period from 2016 to 2017 in the Tissue Culture Laboratory of Vegetable Crops Department Faculty of Agriculture, Alexandria University, Alexandria, Egypt and the experiment was repeated twice at least, with thirty replications.

2-1. Direct shoot induction and bulblets formation

\subsubsection{Preparation of garlic bulbs}

Garlic bulbs were stored at $4^{\circ} \mathrm{C}$, for two months. Bare cloves were rinsed in running tap water for one hour. Healthy cloves were surfacesterilized by soaking in $70 \%$ ethanol for $30 \mathrm{sec}$. under laminar air flow cabinet, the bare cloves were then rinsed for $20 \mathrm{~min}$ in commercial bleach (Clorex (R) at $5.25 \%$ sodium hypochlorite $(\mathrm{NaOCl})$ with two drops of Tween 80 and washed three times using autoclaved distilled water.

2.1.2 Direct shoot organogenesis and bulblets formation

Thirty basal part of the clove of the six selected landraces (Table, 1) were divided into four sections (1x1 mm approx.) and cultured on Murashige and Skoog (1962). The medium was solidified with 0.7 $\%$ (w/v) agar-agar technical, and supplemented with different concentrations of sucrose and jasmonic acid as follow; MS medium supplemented with 30 $\mathrm{g} / 1$ sucrose (control T-1), MS medium supplemented with $30 \mathrm{~g} / 1$ sucrose and $2 \mathrm{mg} / 1$ jasmonic acid (T-2) and MS medium supplemented with $60 \mathrm{~g} / 1$ sucrose and $2 \mathrm{mg} / \mathrm{l}$ jasmonic acid (T-3). Finally, the prepared medium was autoclaved for 20 min under $1.2 \mathrm{~kg} / \mathrm{cm}^{2}$ and $121^{\circ} \mathrm{C}$, then incubated under $16-\mathrm{h}$ photoperiod (under fluorescent light) and $28 \pm 1^{\circ} \mathrm{C}$. Each experiment was repeated twice at least. The following parameters for each explant were evaluated after 9 weeks of culture as survival explants(\%) after 3 weeks on the first culture medium, number of shoots per explant, number of bulblets per explant, average bulblet weight (mg) and total no. of bulblets per clove . Total bulblets no. $/$ clove $=$ (bulblets no. per explant $\times 4$ (no of explant /clove basal part) $\times(1 /$ explant survival rate)).

\subsection{Synthetic seeds (synseed) production}

Synthetic seeds were obtained by immersing bulblets obtained from invitro experiment in gel matrix (3\% Sodium alginate solution at 3\% supplemented with Activated charcoal $0.2 \%$ and antibiotic mixture $0.25 \mathrm{ml} / \mathrm{L}$ ), and exposure to calcium chloride solution (2.5\%), and stirred continuously for $30 \mathrm{~min}$ for hardening (Bekheet, 2006). The bulblets were immersed into calcium chloride solution and stirred continuously for twenty minutes. The encapsulated bulblets were washed twice with sterilized distilled water and transferred to autoclaved petri dishes and stored at $4{ }^{\circ} \mathrm{C}$ for two months to overcome bulblets dormancy. For the plantlets recovery, the stored encapsulated bulblets were immersed in distilled water for 2-3 $\mathrm{min}$ to thaw sodium alginate. Washed bulblets were sowing in pots $(5 \times 5 \mathrm{~cm})$ in unsterilized soil mixture consisted of peat-moss, sand and soil (1:1:1) and kept under greenhouse conditions.

To test the vitality of garlic synthetic seeds and clear up its reliability as a garlic invitro propagation method for synseeds of encapsulated bulblets data on germination percentage and number of days to germination were recorded.

Statistical analysis twenty replicates were chosen to represent each treatment in Complete Randomized Design (CRD) as factorial experiment with two factors (six different landrace and three different media compositions). The analysis done using co-stat software 2004.

\section{RESULTS AND DISCUSSION}

\section{1-Field experiments}

\section{1. Vegetative growth characters}

The results of the field experiments on vegetative growth characters reflected high significant differences among the evaluated landraces for all studied characters during both seasons (Table, 4). In General, "Borg El-Arab" landrace plants recorded significantly the highest mean values for plant height $(88.0$ and $63.0 \mathrm{~cm})$, and highest value of number of leaves / plant, especially in the second season and foliage fresh weight (46.5 and $43.6 \mathrm{~g}$ ) during both seasons.

As for Foliage dry matter content, the values ranged from 16.7 to $26.5 \%$ and from 16.8 to $24.7 \%$ in the first and second growing seasons, respectively. 
Table 4: Vegetative growth characters of 27 landraces grown under Borg El-Arab conditions, Egypt during the winter seasons of $2015 / 2016$.

\begin{tabular}{|c|c|c|c|c|c|c|c|c|}
\hline \multirow{2}{*}{ Landrace } & \multicolumn{2}{|c|}{$\begin{array}{c}\text { Plant height } \\
(\mathrm{cm})\end{array}$} & \multicolumn{2}{|c|}{$\begin{array}{c}\text { Plant leaves } \\
\text { number }\end{array}$} & \multicolumn{2}{|c|}{$\begin{array}{l}\text { Foliage fresh weight } \\
\text { (g) }\end{array}$} & \multicolumn{2}{|c|}{$\begin{array}{c}\text { Foliage dry weight } \\
(\%)\end{array}$} \\
\hline & 2015 & 2016 & 2015 & 2016 & 2015 & 2016 & 2015 & 2016 \\
\hline Balady & $71.00 \mathrm{~d}-\mathrm{h}$ & $52.50 \mathrm{bc}$ & $8.00 a-d$ & $4.67 \mathrm{e}-\mathrm{g}$ & $24.23 \mathrm{e}-\mathrm{g}$ & $13.04 \mathrm{hi}$ & $17.93 \mathrm{~g}-\mathrm{i}^{\mathrm{z}}$ & $17.99 \mathrm{i}-1$ \\
\hline Balady-Al Wadi & $80.22 a-c$ & $54.00 \mathrm{bc}$ & $8.55 a-c$ & $5.27 \mathrm{c}-\mathrm{e}$ & $23.93 \mathrm{e}-\mathrm{g}$ & $16.50 \mathrm{ef}$ & 17.30hi & $18.13 \mathrm{i}-1$ \\
\hline Clone-1 & $83.17 \mathrm{ab}$ & $34.22 \mathrm{e}$ & $8.44 a-c$ & $4.45 \mathrm{f}-\mathrm{h}$ & $31.07 \mathrm{c}$ & $24.11 \mathrm{c}$ & $17.36 \mathrm{~g}-\mathrm{i}$ & $17.84 \mathrm{j}-1$ \\
\hline Clone-5 & $67.78 \mathrm{f}-\mathrm{h}$ & $54.67 \mathrm{ab}$ & $7.89 b-d$ & $5.69 \mathrm{bc}$ & $19.73 \mathrm{~g}-\mathrm{k}$ & $10.93 \mathrm{ij}$ & $18.18 \mathrm{~g}-\mathrm{i}$ & $17.98 \mathrm{i}-1$ \\
\hline Clone-18 & $78.22 \mathrm{~b}-\mathrm{e}$ & $54.50 \mathrm{ab}$ & $8.56 a-c$ & $4.50 \mathrm{f}-\mathrm{h}$ & $35.62 \mathrm{~b}$ & $17.86 \mathrm{e}$ & $17.96 \mathrm{~g}-\mathrm{i}$ & $17.36 \mathrm{kl}$ \\
\hline Clone-22-W & $70.44 d-h$ & $55.00 \mathrm{ab}$ & $8.34 \mathrm{a}-\mathrm{c}$ & $5.25 \mathrm{c}-\mathrm{e}$ & 19.12h-1 & $18.84 \mathrm{de}$ & $17.86 \mathrm{~g}-\mathrm{i}$ & 16.821 \\
\hline Clone-24 & $85.44 \mathrm{ab}$ & $53.39 \mathrm{bc}$ & $9.22 \mathrm{a}$ & $5.57 b-d$ & $38.43 \mathrm{~b}$ & $16.21 \mathrm{e}-\mathrm{g}$ & $18.43 \mathrm{f}-\mathrm{i}$ & $19.51 \mathrm{~g}-\mathrm{i}$ \\
\hline Clone-25 & $70.00 \mathrm{e}-\mathrm{h}$ & $56.00 \mathrm{ab}$ & $6.44 \mathrm{ef}$ & $5.50 \mathrm{~b}-\mathrm{d}$ & $20.04 \mathrm{~g}-\mathrm{j}$ & $13.39 \mathrm{~g}-\mathrm{i}$ & $17.86 \mathrm{~g}-\mathrm{i}$ & $17.35 \mathrm{kl}$ \\
\hline El Ewinat & 70.56d-h & $47.00 \mathrm{bc}$ & $8.00 \mathrm{a}-\mathrm{d}$ & $5.69 \mathrm{bc}$ & $15.15 \mathrm{k}-\mathrm{m}$ & $11.99 \mathrm{hi}$ & $18.05 \mathrm{~g}-\mathrm{i}$ & $18.00 \mathrm{i}-1$ \\
\hline Farmer's clone & $68.44 \mathrm{f}-\mathrm{h}$ & $45.33 \mathrm{~cd}$ & $6.55 \mathrm{ef}$ & $4.53 \mathrm{f}-\mathrm{h}$ & $15.77 \mathrm{j}-\mathrm{m}$ & $6.13 \mathrm{k}$ & $19.22 \mathrm{e}-\mathrm{h}$ & $19.87 \mathrm{f}-\mathrm{h}$ \\
\hline Salaqus-3 & $69.22 \mathrm{e}-\mathrm{h}$ & $50.00 \mathrm{bc}$ & $8.22 \mathrm{a}-\mathrm{c}$ & $5.00 \mathrm{~d}-\mathrm{f}$ & $23.95 \mathrm{e}-\mathrm{g}$ & $16.50 \mathrm{ef}$ & $16.65 \mathrm{i}$ & $17.01 \mathrm{kl}$ \\
\hline Aswan & $74.22 \mathrm{c}-\mathrm{f}$ & $37.33 \mathrm{de}$ & $6.89 \mathrm{de}$ & $4.25 \mathrm{~g}-\mathrm{i}$ & 18.13h-m & $16.29 \mathrm{e}-\mathrm{g}$ & $17.87 \mathrm{~g}-\mathrm{i}$ & $18.13 \mathrm{i}-1$ \\
\hline Borg El-Arab & $88.00 \mathrm{a}$ & $63.00 \mathrm{a}$ & $8.67 \mathrm{ab}$ & $6.33 a$ & $46.50 \mathrm{a}$ & $43.62 \mathrm{a}$ & $19.43 \mathrm{e}-\mathrm{h}$ & $20.66 \mathrm{e}-\mathrm{g}$ \\
\hline El Behera & $65.00 \mathrm{f}-\mathrm{i}$ & $56.17 \mathrm{ab}$ & $7.22 \mathrm{c}-\mathrm{e}$ & $5.50 \mathrm{~b}-\mathrm{d}$ & $20.08 \mathrm{~g}-\mathrm{j}$ & $20.85 \mathrm{~d}$ & $19.58 \mathrm{e}-\mathrm{g}$ & $19.12 \mathrm{~h}-\mathrm{j}$ \\
\hline El Fayoum-1 & $72.33 \mathrm{c}-\mathrm{g}$ & $50.33 \mathrm{bc}$ & $7.22 \mathrm{c}-\mathrm{e}$ & $6.00 \mathrm{ab}$ & $21.52 \mathrm{f}-\mathrm{h}$ & $14.82 \mathrm{f}-\mathrm{h}$ & $18.98 \mathrm{e}-\mathrm{h}$ & $19.33 g-j$ \\
\hline El Fayoum-2 & $79.22 b-d$ & $50.00 \mathrm{bc}$ & $7.89 \mathrm{~b}-\mathrm{d}$ & $5.03 \mathrm{c}-\mathrm{f}$ & $26.68 \mathrm{de}$ & $11.86 \mathrm{hi}$ & $20.72 \mathrm{de}$ & $18.51 \mathrm{~h}-\mathrm{k}$ \\
\hline Egaseed-1A & $55.67 \mathrm{jk}$ & $16.83 \mathrm{~h}$ & $8.22 \mathrm{a}-\mathrm{c}$ & $5.00 \mathrm{~d}-\mathrm{f}$ & $25.98 \mathrm{~d}-\mathrm{f}$ & $11.71 \mathrm{hi}$ & $21.98 \mathrm{~cd}$ & $21.71 \mathrm{de}$ \\
\hline Egaseed-1B & $67.22 \mathrm{f}-\mathrm{h}$ & $19.28 \mathrm{~h}$ & $7.67 b-e$ & $3.99 \mathrm{~h}-\mathrm{j}$ & $20.72 \mathrm{~g}-\mathrm{i}$ & $8.52 \mathrm{jk}$ & $23.58 \mathrm{bc}$ & $22.50 \mathrm{~b}-\mathrm{d}$ \\
\hline Egaseed-2 & $69.56 \mathrm{e}-\mathrm{h}$ & $37.29 \mathrm{de}$ & $5.67 \mathrm{f}$ & $4.00 \mathrm{~h}-\mathrm{j}$ & $30.10 \mathrm{~cd}$ & $32.87 \mathrm{~b}$ & $21.96 \mathrm{~cd}$ & $23.54 \mathrm{ab}$ \\
\hline Egaseed-3 & $51.78 \mathrm{k}$ & $29.28 \mathrm{e}-\mathrm{g}$ & $7.22 \mathrm{c}-\mathrm{e}$ & $3.87 \mathrm{~h}-\mathrm{j}$ & $14.03 \mathrm{~m}$ & $7.19 \mathrm{k}$ & $22.51 \mathrm{~cd}$ & $22.62 b-d$ \\
\hline Sids-40-R.S. & $62.89 \mathrm{~g}-\mathrm{j}$ & $22.00 \mathrm{gh}$ & $7.22 \mathrm{c}-\mathrm{e}$ & $4.00 \mathrm{~h}-\mathrm{j}$ & $24.03 \mathrm{e}-\mathrm{g}$ & $14.66 \mathrm{f}-\mathrm{h}$ & $20.40 d-f$ & $21.28 \mathrm{~d}-\mathrm{f}$ \\
\hline Sids-40-Ayat & $64.89 \mathrm{f}-\mathrm{i}$ & $31.44 \mathrm{ef}$ & $8.00 \mathrm{a}-\mathrm{d}$ & $3.90 \mathrm{~h}-\mathrm{j}$ & $16.90 \mathrm{~h}-\mathrm{m}$ & $10.64 \mathrm{ij}$ & $22.38 \mathrm{~cd}$ & $21.95 \mathrm{c}-\mathrm{e}$ \\
\hline Clone-21 & $55.22 \mathrm{jk}$ & $36.67 \mathrm{e}$ & 7.56b-e & $4.67 \mathrm{e}-\mathrm{g}$ & 19.17h-1 & $13.11 \mathrm{hi}$ & $23.72 b c$ & $24.71 \mathrm{a}$ \\
\hline Clone-22-R & $61.67 \mathrm{~h}-\mathrm{j}$ & $29.44 \mathrm{e}-\mathrm{g}$ & $7.67 b-e$ & $3.60 \mathrm{ij}$ & $16.63 \mathrm{i}-\mathrm{m}$ & $7.38 \mathrm{k}$ & $25.80 \mathrm{a}$ & $24.40 \mathrm{a}$ \\
\hline Al Ayat-1 & $48.67 \mathrm{k}$ & $20.33 \mathrm{~h}$ & $8.55 \mathrm{a}-\mathrm{c}$ & $3.77 \mathrm{ij}$ & $15.72 \mathrm{j}-\mathrm{m}$ & $8.53 \mathrm{jk}$ & $25.18 \mathrm{ab}$ & $23.69 \mathrm{ab}$ \\
\hline Bany gonamy & $65.22 \mathrm{f}-\mathrm{i}$ & $29.72 \mathrm{e}-\mathrm{g}$ & $8.22 \mathrm{a}-\mathrm{c}$ & $3.65 \mathrm{ij}$ & $24.27 \mathrm{e}-\mathrm{g}$ & $6.69 \mathrm{k}$ & $26.48 \mathrm{a}$ & $24.27 \mathrm{a}$ \\
\hline Salaqus & $57.22 \mathrm{i}-\mathrm{k}$ & $24.50 \mathrm{f}-\mathrm{h}$ & $7.56 \mathrm{~b}-\mathrm{e}$ & $3.50 \mathrm{j}$ & $14.941 \mathrm{~m}$ & $8.50 \mathrm{jk}$ & $26.42 \mathrm{a}$ & 23.29a-c \\
\hline
\end{tabular}

*Values followed by the same alphabetical letter(s) in common, within a particular group of means in each character, do not significantly differ, using Duncan's multiple range test at 0.05 level of probability.

Bany gonamy, 'Salaqus' and 'Clone-22-R' recorded the highest values for foliage dry matter content (26.5, 26.4 and $25.8 \%$, respectively) followed by 'Al Ayat-1' (25.2\%). However, the lowest mean values for foliage dry matter content were recorded for 'Salaqus-3' and 'Clone-22-W' (16.7 and 16.8\%) in both seasons. Such results emphasized the fact that vegetative traits depended on studied genotypes. The differences among garlic local cultivars and ecotypes may be due to either incidence of genetics differences among them and/or to interaction among genotypes, soil properties and weather conditions. Therefore, an important evaluation of genotypes under different environments, which could highlight on the superior genotypes under various growth condition, in order to reach the highest productivity (Metwally and ElDenary, 2003; Obiadalla, 2014) , Al-Otayk et al., (2008), Moustafa et al., (2009), Dawood, (2011), Ahmed (2012), Abou El-Magd et al. (2012), Anwar (2012) and Youssef and Tony (2014), whose mentioned that there were a wide and great variation on vegetative growth of most garlic cultivars.

\subsection{Bulb characteristics:}

Average values measured in Table (5), and demonstrated in Figure (1) show the differences among studied garlic landraces for bulb characteristics. For bulb diameter "Egaseed-1B" recorded the highest significant average value for bulb diameter $(46.00 \mathrm{~mm})$. Insignificant differences were observed between 'Egaseed-1B' and each of 'Sids-40- R.S.', 'Sids-40-Ayat', 'Bany gonamy', 'Egaseed-1A', 'Clone-22-R' and 'Salaqus', (44.44, $43.33,42.89,41.22,40.67$ and $39.67 \mathrm{~mm}$, respectively ), in the first growing season. While in the second season, landrace 'Borg El-Arab' gave the highest average bulb diameter $(43.18 \mathrm{~mm})$ followed insignificantly by 'Al Ayat-1', 'Egaseed-2' and 'Clone-18' which gave 43.00, 42.08 and $40.93 \mathrm{~mm}$, respectively.

'El Ewinat', 'Clone-5', and 'Clone-22-W' had the lowest bulb diameter $(29.44,29.44$, and 27.33 $\mathrm{mm}$, respectively) in the first growing season. 'Farmer's clone' recorded the lowest bulb diameter value in both growing seasons (28.89 and 27.47 $\mathrm{mm}$, respectively). 
Bulb dry matter percentage ranged from 36.6 to $45.68 \%$ and from 35.07 to $44.89 \%$ during the first and second growing season, respectively. The highest value was recorded for 'Egaseed-2' (45.68 $\%)$ in the first growing season. During the second season, 'Egaseed-1A', 'Egaseed-2' and 'Clone-21' landraces gave high bulb dry matter (44.89, 44.87 and $44.54 \%$, respectively). On the other hand, 'Clone-1' showed significantly lower dry matter percentage (35.80 and $35.07 \%$ ) in the first and second seasons, respectively. Regarding the average cloves number per bulb, the value ranged from 9.33 to 40.00 and from 3.55 to 32.71 in the first and second growing seasons, respectively. Landrace E1 Fayoum-1 had the highest cloves number per bulb (40.00 cloves/ bulb) and as shown in Figure (1). In the second season 'Borg El-Arab' and 'El Fayoum1' scored the highest cloves number no. / Bulb (32.71 and 32.64 cloves/ bulb, respectively). The results indicated that, cloves number/bulb varied significantly among different landraces, as well as been affected by growing conditions under Borg Al Arab, Egypt conditions. The stability of 'Egaseed2', 'Egaseed - B1' and 'Borg El-Arab' landraces for bulb characteristics during the consecutive years of the study may due to their adaptation for cultivation under Borg El-Arab conditions.

As regards to average clove weight, Bany gonamy landrace gave the heaviest average clove weight $(5.19$ g) compared with other studied landraces, in the first season. While, in the second season, 'Clone-22-R', 'Sids-40-Ayat' and 'Sids-40R.S', Superseded significantly, all of the other studied landraces for the average clove weight, 5.40, 5.33 and $5.05 \mathrm{~g}$, respectively.

Phenotypic diversity evaluation showed wide and great variations on vegetative growth that help in improving garlic breeding and production of elite varieties. Evaluation of landraces under different environment conditions could highlight the superior landrace/s to achieve the highest productivity. This study agreed with the finding of Saraf et al., 2000, Baghalian et al., (2006, Metwally and El-Denary, 2003, Al-Otayk et al., 2008, Moustafa et al., 2009; Dawood, 2011; Ahmed 2012; Abou El-Magd et al., 2012; Anwar 2012; Abu El-Oyun, 2010; Helmy et al., 2011, Kumar et al.,(2017) and Youssef and Tony, 2014.

Table 5: Bulb characteristics of 27 landraces grown under Borg El-Arab conditions, Egypt during the winter seasons of $2015 / 2016$.

\begin{tabular}{|c|c|c|c|c|c|c|c|c|}
\hline \multirow{2}{*}{ Candrace } & \multicolumn{2}{|c|}{$\begin{array}{c}\text { Average bulb } \\
\text { diameter (mm) }\end{array}$} & \multicolumn{2}{|c|}{$\begin{array}{l}\text { Bulb dry matter } \\
\text { content }(\%)^{\mathrm{z}}\end{array}$} & \multicolumn{2}{|c|}{$\begin{array}{c}\text { Average cloves } \\
\text { number per bulb }\end{array}$} & \multicolumn{2}{|c|}{$\begin{array}{c}\text { Average clove } \\
\text { weight (g) }\end{array}$} \\
\hline & 2015 & 2016 & 2015 & 2016 & 2015 & 2016 & 2015 & 2016 \\
\hline Balady & $32.22 \mathrm{f}-\mathrm{i}$ & $28.49 \mathrm{i}-\mathrm{k}$ & $38.55 \mathrm{e}-\mathrm{h}$ & $37.90 \mathrm{f}-\mathrm{j}$ & $24.33 \mathrm{e}-\mathrm{g}$ & $23.09 \mathrm{c}-\mathrm{f}$ & $0.93 \mathrm{f}$ & $0.54 \mathrm{f}$ \\
\hline Balady- Al Wadi & $31.33 \mathrm{~g}-\mathrm{i}$ & $31.90 \mathrm{e}-\mathrm{j}$ & $38.03 \mathrm{e}-\mathrm{h}$ & $37.33 \mathrm{~g}-\mathrm{j}$ & $34.00 \mathrm{a}-\mathrm{d}$ & $25.16 \mathrm{~b}-\mathrm{e}$ & $0.73 \mathrm{f}$ & $0.67 f$ \\
\hline Clone-1 & $36.78 \mathrm{c}-\mathrm{h}$ & $32.80 \mathrm{~d}-\mathrm{h}$ & $35.80 \mathrm{~h}$ & $35.07 \mathrm{j}$ & $35.33 \mathrm{a}-\mathrm{c}$ & $31.06 \mathrm{ab}$ & $0.71 \mathrm{f}$ & $0.62 \mathrm{f}$ \\
\hline Clone-5 & $29.44 \mathrm{i}$ & 29.33 g-k & $37.78 \mathrm{f}-\mathrm{h}$ & $36.86 \mathrm{~g}-\mathrm{j}$ & $22.67 \mathrm{e}-\mathrm{h}$ & $19.22 \mathrm{ef}$ & $0.89 \mathrm{f}$ & $0.59 \mathrm{f}$ \\
\hline Clone-18 & $32.78 \mathrm{e}-\mathrm{i}$ & $40.93 \mathrm{ab}$ & $38.17 \mathrm{e}-\mathrm{h}$ & $37.34 \mathrm{~g}-\mathrm{j}$ & $31.67 \mathrm{a}-\mathrm{e}$ & $25.14 \mathrm{~b}-\mathrm{e}$ & $0.89 \mathrm{f}$ & $0.58 \mathrm{f}$ \\
\hline Clone-22-W & $27.33 \mathrm{i}$ & $28.25 \mathrm{jk}$ & $38.12 \mathrm{e}-\mathrm{h}$ & $37.32 \mathrm{~g}-\mathrm{j}$ & $25.00 \mathrm{~d}-\mathrm{g}$ & $29.68 \mathrm{a}-\mathrm{c}$ & $0.55 \mathrm{f}$ & $0.45 \mathrm{f}$ \\
\hline Clone-24 & $33.00 \mathrm{e}-\mathrm{i}$ & $28.73 \mathrm{~h}-\mathrm{k}$ & $36.60 \mathrm{gh}$ & $35.49 \mathrm{ij}$ & $37.33 \mathrm{ab}$ & $29.08 \mathrm{a}-\mathrm{d}$ & $0.81 \mathrm{f}$ & $0.43 \mathrm{f}$ \\
\hline Clone-25 & $32.00 \mathrm{f}-\mathrm{i}$ & $33.87 \mathrm{c}-\mathrm{f}$ & $41.21 \mathrm{~b}-\mathrm{f}$ & $39.43 c-h$ & $26.67 \mathrm{c}-\mathrm{g}$ & $27.32 \mathrm{a}-\mathrm{d}$ & $0.84 \mathrm{f}$ & $0.48 \mathrm{f}$ \\
\hline El Ewinat & $29.44 \mathrm{i}$ & $28.21 \mathrm{jk}$ & $37.39 \mathrm{f}-\mathrm{h}$ & $36.47 \mathrm{~h}-\mathrm{j}$ & $22.33 \mathrm{e}-\mathrm{h}$ & $20.33 \mathrm{ef}$ & $0.61 \mathrm{f}$ & $0.53 \mathrm{f}$ \\
\hline Farmer's clone & $28.89 \mathrm{i}$ & $27.47 \mathrm{k}$ & $36.92 \mathrm{f}-\mathrm{h}$ & $35.89 \mathrm{~h}-\mathrm{j}$ & $27.67 \mathrm{c}-\mathrm{g}$ & $25.55 \mathrm{~b}-\mathrm{e}$ & $0.72 \mathrm{f}$ & $0.30 \mathrm{f}$ \\
\hline Salaqus-3 & $30.44 \mathrm{hi}$ & $34.85 \mathrm{c}-\mathrm{e}$ & $39.86 \mathrm{c}-\mathrm{h}$ & $39.20 \mathrm{~d}-\mathrm{i}$ & $26.00 \mathrm{~d}-\mathrm{g}$ & $20.33 \mathrm{ef}$ & $0.77 \mathrm{f}$ & $0.69 \mathrm{f}$ \\
\hline Aswan & $34.11 \mathrm{~d}-\mathrm{i}$ & $34.31 \mathrm{c}-\mathrm{e}$ & $40.63 \mathrm{c}-\mathrm{g}$ & $39.26 \mathrm{~d}-\mathrm{i}$ & $37.67 \mathrm{a}$ & $29.55 a-c$ & $0.65 \mathrm{f}$ & $0.74 \mathrm{f}$ \\
\hline Borg El-Arab & $38.67 \mathrm{~b}-\mathrm{f}$ & $43.18 \mathrm{a}$ & $37.28 \mathrm{f}-\mathrm{h}$ & $37.55 f-j$ & $37.00 \mathrm{ab}$ & $32.71 \mathrm{a}$ & $1.15 \mathrm{f}$ & $1.18 \mathrm{f}$ \\
\hline El Behera & $30.33 \mathrm{hi}$ & $35.36 \mathrm{c}-\mathrm{e}$ & $42.46 \mathrm{a}-\mathrm{e}$ & $40.59 \mathrm{~b}-\mathrm{g}$ & $31.67 \mathrm{a}-\mathrm{e}$ & $17.25 \mathrm{f}$ & $0.66 \mathrm{f}$ & $1.24 \mathrm{f}$ \\
\hline El Fayoum-1 & $30.78 \mathrm{~g}-\mathrm{i}$ & $28.27 \mathrm{jk}$ & $36.85 \mathrm{f}-\mathrm{h}$ & $35.74 \mathrm{~h}-\mathrm{j}$ & $40.00 \mathrm{a}$ & $32.64 a$ & $0.40 \mathrm{f}$ & $0.34 \mathrm{f}$ \\
\hline E1 Fayoum-2 & $34.11 \mathrm{~d}-\mathrm{i}$ & $30.13 \mathrm{f}-\mathrm{k}$ & $38.70 \mathrm{e}-\mathrm{h}$ & $38.35 \mathrm{e}-\mathrm{j}$ & $28.33 b-f$ & $22.83 d-f$ & $0.83 \mathrm{f}$ & $0.45 \mathrm{f}$ \\
\hline Egaseed-1A & $41.22 \mathrm{a}-\mathrm{c}$ & $29.82 \mathrm{f}-\mathrm{k}$ & $43.72 \mathrm{a}-\mathrm{d}$ & $44.89 \mathrm{a}$ & $14.67 \mathrm{~h}-\mathrm{j}$ & $5.66 \mathrm{~g}$ & $2.94 \mathrm{~cd}$ & $3.38 \mathrm{de}$ \\
\hline Egaseed-1B & $46.00 \mathrm{a}$ & $37.45 \mathrm{bc}$ & $43.67 \mathrm{a}-\mathrm{d}$ & $40.75 b-g$ & $13.33 \mathrm{ij}$ & $5.06 \mathrm{~g}$ & $3.99 \mathrm{~b}$ & $4.32 \mathrm{bc}$ \\
\hline Egaseed-2 & $33.89 \mathrm{~d}-\mathrm{i}$ & $42.08 \mathrm{a}$ & $45.68 \mathrm{a}$ & $44.87 \mathrm{a}$ & $9.33 \mathrm{j}$ & $9.11 \mathrm{~g}$ & $2.34 \mathrm{dc}$ & $2.62 \mathrm{e}$ \\
\hline Egaseed-3 & $37.78 \mathrm{~b}-\mathrm{g}$ & $36.62 \mathrm{~cd}$ & $45.22 \mathrm{ab}$ & $41.94 \mathrm{a}-\mathrm{e}$ & $11.33 \mathrm{ij}$ & $3.90 \mathrm{~g}$ & $2.86 \mathrm{~cd}$ & $4.25 \mathrm{bcd}$ \\
\hline Sids-40-R.S. & $44.44 \mathrm{Ab}$ & $33.13 \mathrm{~d}-\mathrm{g}$ & $40.15 \mathrm{c}-\mathrm{h}$ & $43.02 \mathrm{a}-\mathrm{d}$ & $12.00 \mathrm{ij}$ & $6.18 \mathrm{~g}$ & $4.26 \mathrm{~b}$ & $5.05 \mathrm{ab}$ \\
\hline Sids-40-Ayat & $43.33 \mathrm{a}-\mathrm{c}$ & $33.20 \mathrm{~d}-\mathrm{g}$ & $39.59 d-h$ & $40.59 \mathrm{~b}-\mathrm{g}$ & $12.33 \mathrm{ij}$ & $4.20 \mathrm{~g}$ & $3.24 \mathrm{c}$ & $5.33 \mathrm{a}$ \\
\hline Clone-21 & $37.22 \mathrm{c}-\mathrm{h}$ & $32.34 \mathrm{e}-\mathrm{j}$ & $44.12 \mathrm{a}-\mathrm{c}$ & $44.54 \mathrm{a}$ & $18.33 \mathrm{~g}-\mathrm{j}$ & $7.12 \mathrm{~g}$ & $1.99 \mathrm{e}$ & $3.34 \mathrm{de}$ \\
\hline Clone-22-R & 40.67 a-d & $36.70 \mathrm{~cd}$ & $44.15 \mathrm{a}-\mathrm{c}$ & $43.92 \mathrm{ab}$ & $19.67 \mathrm{f}-\mathrm{i}$ & $3.55 \mathrm{~g}$ & $2.20 \mathrm{de}$ & $5.40 \mathrm{a}$ \\
\hline Al Ayat-1 & $38.89 \mathrm{~b}-\mathrm{f}$ & $43.00 \mathrm{a}$ & $40.07 \mathrm{c}-\mathrm{h}$ & $43.15 \mathrm{a}-\mathrm{c}$ & $12.00 \mathrm{ij}$ & $4.18 \mathrm{~g}$ & $2.81 \mathrm{~cd}$ & $4.10 \mathrm{~cd}$ \\
\hline Bany gonamy & $42.89 \mathrm{a}-\mathrm{c}$ & 28.82 h-k & $43.64 a-d$ & 41.31a-f & $10.50 \mathrm{ij}$ & $5.18 \mathrm{~g}$ & $5.19 \mathrm{a}$ & $2.94 \mathrm{e}$ \\
\hline Salaqus & $39.67 \mathrm{a}-\mathrm{e}$ & $32.62 \mathrm{~d}-\mathrm{i}$ & $39.67 \mathrm{~d}-\mathrm{h}$ & $42.72 a-d$ & $11.67 \mathrm{ij}$ & $4.91 \mathrm{~g}$ & $2.92 \mathrm{~cd}$ & $4.34 \mathrm{bc}$ \\
\hline
\end{tabular}




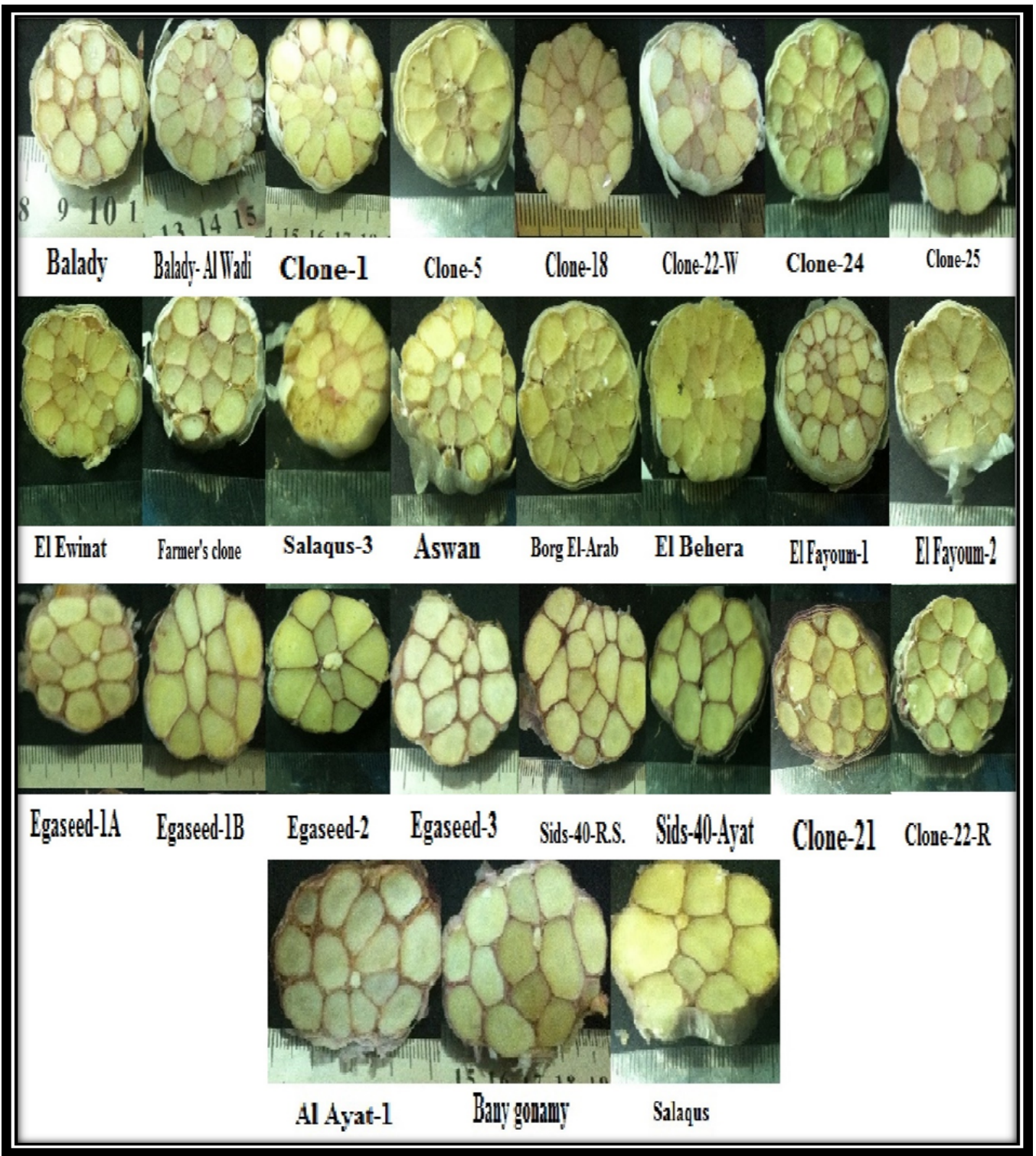

Figure 1: Cross section of the 27 garlic local cultivars and ecotypes bulbs at harvest in Borg El-Arab during the growing season of 2015/2016.

They reported the existence of wide and great variations on vegetative growth of most Egyptian garlic cultivars. Moreover, Obiadalla, (2014) observed significant variations of vegetative characters among the twelve studied Balady landraces which were collected from different Egyptian governorate.

\section{In vitro propagation experiment}

2. 1. Direct shoot induction and bulblets formation

Selected garlic landraces varied expressively for their studied characters under in vitro conditions (Table 5). Regarding the regeneration percentage no such significance was observed between different tested treatments. Whereas, Aswan landrace differed significantly, more or less from the others. It gave the least regeneration percentage compared to the other landraces. 'Salaqus-3' scored the greatest mean number of shoots (6.67) and bulblets ranged from 3.3 / explant for Sids-40- Ayat to 3.1 / explant for Clone-21 compared with other landraces. On the other hand, the first order interaction between $\mathrm{T} 3 \mathrm{x}$ Aswan gave the highest average value (8.7 shots/ explant, meanwhile the lowest average value 3.0 was recorded due to the interaction between $\mathrm{T} 2 \mathrm{x}$ Sids-40- Ayat.

Sucrose and jasmonic acid and played major roles of media efficiency regarding germination, number of shoots and number of bulblets per explants. Application of sucrose and JA resulted 
significant differences for the number of bulblets per explant among studied treatments. Explants cultured on MS medium supplemented with $6 \%$ sucrose and $2 \mathrm{mg} / \mathrm{L}$ jasmonic (T3) gave the highest significant number of bulblets (3.8) / explant compared with that cultured on jasmonic free media (T-1) or supplemented with $3 \%$ sucrose and $2 \mathrm{mg} / \mathrm{L}$ JA (T-2). Concerning the interaction among landraces and used media, the results indicated highly significant differences for number of shoot and bulblets formation based on the structure of the used media, (Table, 5 and Figure, 2). Explants of 'Aswan' landrace cultured on Ms medium supplemented with $6 \%$ sucrose and $2 \mathrm{mg} / \mathrm{L} \mathrm{JA}$; gave highest numbers of shoot and bulblets / explant (8.7 and 7.0, respectively) compared with other landraces and treatments used except for 'Borg ElArab' and 'El Behera' landraces, (Figure, 2).

The results of Table (6) show the influence of MS media supplemented with different sucrose levels and jasmonic acid on bulblets formation percentage, total number of bulblets per clove and average bulblet weight of the six garlic landraces cultured for 9 weeks. The landraces of 'Salaqus-3' and 'Borg El-Arab' scored the highest significantly number of bulblets/clove (12.00 and 11.80 bulblets/ cloves, respectively). While, 'Sids-40-Ayat' and 'Clone-21' recorded the lowest values for number of bulblets/ cloves (5.16 and 5.38 bulblets/ cloves, respectively). However, the treatment $\mathrm{T}-3$ (6\% sucrose $+2.00 \mathrm{mg} / \mathrm{l}$ jasmonic acid) achieved the greatest significant number of bulblets/clove (12.61 bulblets/ explant). While, T-1 treatments (control; $3 \%$ sucrose) exhibited the lowest number of bulblets per clove (4.82 bulblets/clove). Moreover, total number of bulblets/clove which formed on T-2 $(3 \%$ sucrose $+2.00 \mathrm{mg} / 1$ jasmonic acid) gave moderate (8.73 bulblets/clove) and was not clearly differed from T-3 and T-1 media. Finally different media had insignificant effect on the number of bulblets/explants.

Table 6: the Influence of MS media supplemented with different sucrose levels and jasmonic acid on regeneration percentage, number of shoots and bulblets per explant of six garlic landraces cultured invitro for 3 weeks.

\begin{tabular}{|c|c|c|c|c|c|c|c|c|c|c|c|c|}
\hline Lreatment & $\begin{array}{c}\text { T-1 } \\
\text { (cont.) }\end{array}$ & T-2 & T-3 & Mean & $\begin{array}{c}\mathrm{T}-1 \\
\text { (cont.) }\end{array}$ & T-2 & T-3 & Mean & $\begin{array}{c}\mathrm{T}-1 \\
\text { (cont.) }\end{array}$ & T-2 & T-3 & Mean \\
\hline & \multicolumn{4}{|c|}{ Regeneration \% } & \multicolumn{4}{|c|}{ No of shoots / explant } & \multicolumn{4}{|c|}{ No of bulblets / explant } \\
\hline Aswan & $68.3 \mathrm{a}$ & $63.3 \mathrm{a}$ & $68.3 \mathrm{a}$ & $66.7 \mathrm{~B}$ & $3.7 \mathrm{e}-\mathrm{g}$ & $6.0 \mathrm{a}-\mathrm{d}$ & $8.7 \mathrm{a}$ & $6.1 \mathrm{~A}$ & $1.0 \mathrm{~d}$ & $2.7 \mathrm{~b}-\mathrm{d}$ & $7.0 \mathrm{a}$ & $3.6 \mathrm{~A}$ \\
\hline Borg El-Arab & $88.3 \mathrm{a}$ & $88.3 \mathrm{a}$ & $88.3 \mathrm{a}$ & $88.33 \mathrm{~A}$ & $5.7 b-f$ & $7.0 \mathrm{a}-\mathrm{d}$ & $7.0 \mathrm{a}-\mathrm{d}$ & $6.6 \mathrm{~A}$ & $1.3 \mathrm{~cd}$ & $3.7 \mathrm{~b}-\mathrm{d}$ & $4.7 \mathrm{ab}$ & $3.2 \mathrm{~A}$ \\
\hline Sids-40-Ayat & $98.3 \mathrm{a}$ & $91.7 \mathrm{a}$ & $96.7 \mathrm{a}$ & $95.6 \mathrm{~A}$ & $4.3 \mathrm{~d}-\mathrm{g}$ & $3.0 \mathrm{fg}$ & $2.7 \mathrm{~g}$ & $3.3 \mathrm{~B}$ & $1.0 \mathrm{~d}$ & $2.0 \mathrm{~cd}$ & $1.0 \mathrm{~d}$ & $1.3 \mathrm{~B}$ \\
\hline Clone-21 & $93.3 \mathrm{a}$ & $86.7 \mathrm{a}$ & $95.0 \mathrm{a}$ & $91.7 \mathrm{~A}$ & $3.7 \mathrm{e}-\mathrm{g}$ & $3.7 \mathrm{e}-\mathrm{g}$ & $2.0 \mathrm{~g}$ & $3.1 \mathrm{~B}$ & $2.0 \mathrm{~b}-\mathrm{d}$ & $1.0 \mathrm{~d}$ & $1.3 \mathrm{~cd}$ & $1.4 \mathrm{~B}$ \\
\hline Mean & $80.9 \mathrm{~A}$ & $87.9 \mathrm{~A}$ & $86.3 \mathrm{~A}$ & & $4.84 \mathrm{~A}$ & $5.4 \mathrm{~A}$ & $5.6 \mathrm{~A}$ & & $1.3 \mathrm{C}$ & $2.7 \mathrm{~B}$ & $3.8 \mathrm{~A}$ & \\
\hline
\end{tabular}

*Values followed by the same alphabetical letter(s) in common, within a particular group of means in each character, do not significantly differ, using Duncan's multiple range test at 0.05 level of probability

$\mathrm{T} 1, \mathrm{MS}+30 \mathrm{~g}$ sucrose $; \mathrm{T} 2, \mathrm{MS}+30 \mathrm{~g}$ sucrose $+2 \mathrm{mg} / \mathrm{l} \mathrm{JA} ; \mathrm{T} 3, \mathrm{MS}+60 \mathrm{~g}$ sucrose $+2 \mathrm{mg} / 1 \mathrm{JA}$

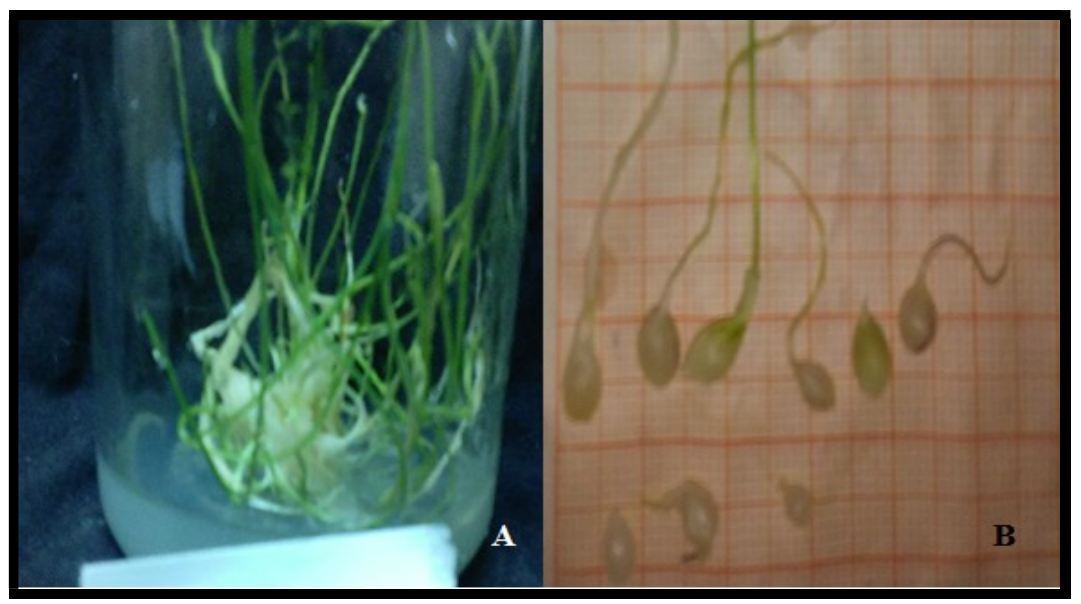

Figure 2: Cluster of EI Behera landrace shoots after 6 weeks invitro (A) and bulblets in hanging mode after 9weeks (B) of culture on MS medium with $6 \%$ sucrose and $2 \mathrm{mg} / \mathrm{l}$ jasmonic acid. 
Significant differences among the six garlic landraces for average bulblet weight $(\mathrm{mg})$ were obtained (Table, 7). High significant differences were observed among studied landraces depending on the application of different media. Regarding the average bulblet weight, Clone- 21 gives the highest average bulblet weight (232.94 $\mathrm{mg})$, while the lowest values scored by 'Aswan' and 'Salaqus-3; landraces (103.47 and $75.24 \mathrm{mg}$. Highest significant bulblet weight $(259.72 \mathrm{mg})$ was verified by control treatment (T-1). While insignificant differences were obtained between $\mathrm{T}-2$ and $\mathrm{T}-3$ which scored the lowest significant mean bulblet weight values (82.70 and $94.63 \mathrm{mg}$ ). Jasmonic acid (JA), jasmonic acid methyl ester and some of their derivatives possess various physiological activities when applied to plants (Koda, 1997). Jasmonates are signal molecules in plant stress responses and are, also, important promoters of plant growth and development. Jasmonic acid stimulates cell division and enlargement also interact with other plant growth substances, e.g., cytokinins (Ravnikar et al., 992 and Takahashi et al., 1995. When JA is added to plant growth medium at concentrations up to 10 $\mu \mathrm{M}$, it expressively stimulates the elongation of axillary buds (Ravnikar et al., 1992). In general, Jasmonates may be involved in the process of storage organ formation. Nojiri et al., 1992 showed that endogenous concentrations of JA were different in the bulbing and non bulbing onion plant parts. The induction of bulb formation by JA was also demonstrated in garlic shoots in vitro (Ravnikar et al., 1993. Jasmonic acid in combination with 2ip stimulates the induction of shoot formation on basal plates of garlic cloves, which further resulted in a high percentage of bulb formation (Ravnikar et al., 1993.

Regarding Sucrose, it is considered another important factor which induces bulb formation in vitro. It was demonstrated that $12 \%$ sucrose promotes bulb induction in garlic (Nagakubo et al., 1993; Yasseen et al., 1994.

\subsection{Synthetic seeds germination (plantlets recovery 2}

Results in Table (7), illustrate synthetic seeds (bulblets - immersed in gel matrix " $3 \% \mathrm{Na}$-alginate" and hardened with $\mathrm{CaCl}_{2} \cdot 2 \mathrm{H}_{2} \mathrm{O}$ solution " $2.5 \%$ " and stirred continuously for $30 \mathrm{~min}$ on a magnetic stirrer, then have been recovered to plantlets in a period ranged from 3 to 19 days from sowing, depending on the genotypic variations and treatments used. Non-germinated synthetic seeds may be due to that stored bulblets did not run out the dormancy. This finding is taken as indicator for synthetic seeds validation when directly uses in open field fig (3). It was clear from Table (7) and fig. (4) that using T-3 treatment $(6 \%$ sucrose and $2 \mathrm{mg} / \mathrm{L}$ jasmonic acid) lead to complete germination for all landraces and decrease the sprouting days.

Concerning synseeds (synthetic seeds), it was reported that the in vitro raised bulblets proved to be efficient micro-propagating unit which did not require acclimatization and can be directly sown into soil (Nagakubo et al., 1997 ). Although, bulbs derived from bulblets planting were smaller than commercial bulbs, they provided cultivar rejuvenation. In addition, that bulbs derived from bulblets will reach an appropriate size after 2 to 3 years of cultivation (Nagakubo et al., 1997).

Regarding in vitro bulblets products, they have been regenerated $(95 \%)$ without acclimatization in autoclaved commercial potting soil under greenhouse conditions (Yasseen et al., 1994). Also, Haque et al. (1998, 2003) and Dixit et al. (2013) revealed that about $80-90 \%$ bulblets were successfully established and survived under field conditions.

Capsulation of in vitro derived products "such as garlic bulblets" provided protection for them against microorganism attack and unwanted germination (Personal observation). In addition, capsulation apply on meristematic organ which formed through tissue culture techniques made them easy handling, transport, delivery and had a long-term storage potentiality (Ghosh and Sen, 1994.

Table 7: The influence of MS media supplemented with different sucrose levels and jasmonic acid on bulblets formation percentage, total number of bulblets per clove and average bulblet weight of six garlic landraces cultured for 9 weeks invitro.

\begin{tabular}{|c|c|c|c|c|c|c|c|c|c|c|c|c|}
\hline Landrace & $\begin{array}{r}\mathrm{T}-1 \\
\text { (cont.) }\end{array}$ & T-2 & T-3 & Mean & $\begin{array}{r}\mathrm{T}-1 \\
\text { (cont.) }\end{array}$ & T-2 & $\mathbf{T}-\mathbf{3}$ & Mean & $\begin{array}{r}\mathrm{T}-1 \\
\text { (cont) }\end{array}$ & T-2 & T-3 & Mean \\
\hline Salaqus-3 & $33.3 \mathrm{a}$ & $100.0 \mathrm{a}$ & $00.0 \mathrm{a}$ & $77.8 \mathrm{~A}$ & $6.7 \mathrm{a}$ & $13.3 \mathrm{a}$ & $16.0 \mathrm{a}$ & $12.0 \mathrm{~A}$ & $41.7 \mathrm{a}$ & $80.2 \mathrm{a}$ & $103.9 \mathrm{a}$ & $75.2 \mathrm{~B}$ \\
\hline Borg El-Arab & $66.7 \mathrm{a}$ & $100.0 \mathrm{a}$ & $00.0 \mathrm{a}$ & $88.9 \mathrm{~A}$ & $4.7 \mathrm{a}$ & $12.3 \mathrm{a}$ & $18.2 \mathrm{a}$ & $11.8 \mathrm{~A}$ & $143.0 \mathrm{a}$ & $56.8 \mathrm{a}$ & $179.1 \mathrm{a}$ & $137.4 \mathrm{AB}$ \\
\hline El Behera & $100.0 \mathrm{a}$ & $100.0 \mathrm{a}$ & $00.0 \mathrm{a}$ & $100.0 \mathrm{~A}$ & $3.1 \mathrm{a}$ & $8.7 \mathrm{a}$ & $12.4 \mathrm{a}$ & $8.1 \mathrm{AB}$ & $290.3 \mathrm{a}$ & $85.0 \mathrm{a}$ & $39.8 \mathrm{a}$ & $138.4 \mathrm{AB}$ \\
\hline Sids-40-Ayat & $100.0 \mathrm{a}$ & $100.0 \mathrm{a}$ & $66.7 \mathrm{a}$ & $88.9 \mathrm{~A}$ & $3.9 \mathrm{a}$ & $7.7 \mathrm{a}$ & $3.9 \mathrm{a}$ & $5.2 \mathrm{~B}$ & $330.0 \mathrm{a}$ & $175.9 \mathrm{a}$ & $54.0 \mathrm{a}$ & $186.6 \mathrm{AB}$ \\
\hline Mean & $83.3 \mathrm{~A}$ & $94.5 \mathrm{~A}$ & $94.5 \mathrm{~A}$ & & $4.8 \mathrm{~B}$ & $7.0 \mathrm{AB}$ & $12.6 \mathrm{~A}$ & & $259.7 \mathrm{~A}$ & $82.7 \mathrm{~B}$ & $94.6 \mathrm{~B}$ & \\
\hline
\end{tabular}

Values followed by the same alphabetical letter(s) in common, within a particular group of means in each character, do not significantly differ, using Duncan's multiple range test at 0.05 level of probability

$\mathrm{T} 1, \mathrm{MS}+30 \mathrm{~g}$ sucrose $; \mathrm{T} 2, \mathrm{MS}+30 \mathrm{~g}$ sucrose $+2 \mathrm{mg} / \mathrm{JA} ; \mathrm{T} 3, \mathrm{MS}+60 \mathrm{~g}$ sucrose $+2 \mathrm{mg} / 1 \mathrm{JA}$ 
Table 8: Plants of garlic synthetic seeds derived from in vitro bulblets planted in peat-moss, sand and soil $(1: 1: 1)$ mixture and irrigated with tap water, under greenhouse condition.

\begin{tabular}{|c|c|c|c|c|c|c|}
\hline \multirow{2}{*}{ Genotype } & \multicolumn{2}{|c|}{$\begin{array}{c}\text { T-1 } \\
\text { (control) } 3 \% \text { Sucrose }\end{array}$} & \multicolumn{2}{|c|}{$\begin{array}{c}\text { T-2 } \\
3 \% \text { Sucrose }+2 \text { mg/l JA }\end{array}$} & \multicolumn{2}{|c|}{$\begin{array}{c}\mathrm{T}-3 \\
6 \% \text { Sucrose }+2 \mathrm{mg} / \mathrm{l} \mathrm{JA}\end{array}$} \\
\hline & G & SD & $\mathbf{G}$ & SD & G & SD \\
\hline Salaqus-3 & + & 6 & + & 18 & + & 9 \\
\hline Aswan & - & - & + & 16 & + & 10 \\
\hline Borg El-Arab & + & 9 & + & 18 & + & 14 \\
\hline El Behera & + & 5 & - & - & + & 6 \\
\hline Sids-40 Ayat & + & 19 & - & - & + & 3 \\
\hline Clone-21 & - & - & - & - & + & 6 \\
\hline
\end{tabular}

$\mathrm{G}=$ Germination, $\mathrm{SD}=$ Sprouting days, the singe "+" synseeds were germinate, "-" synseeds were not germinate

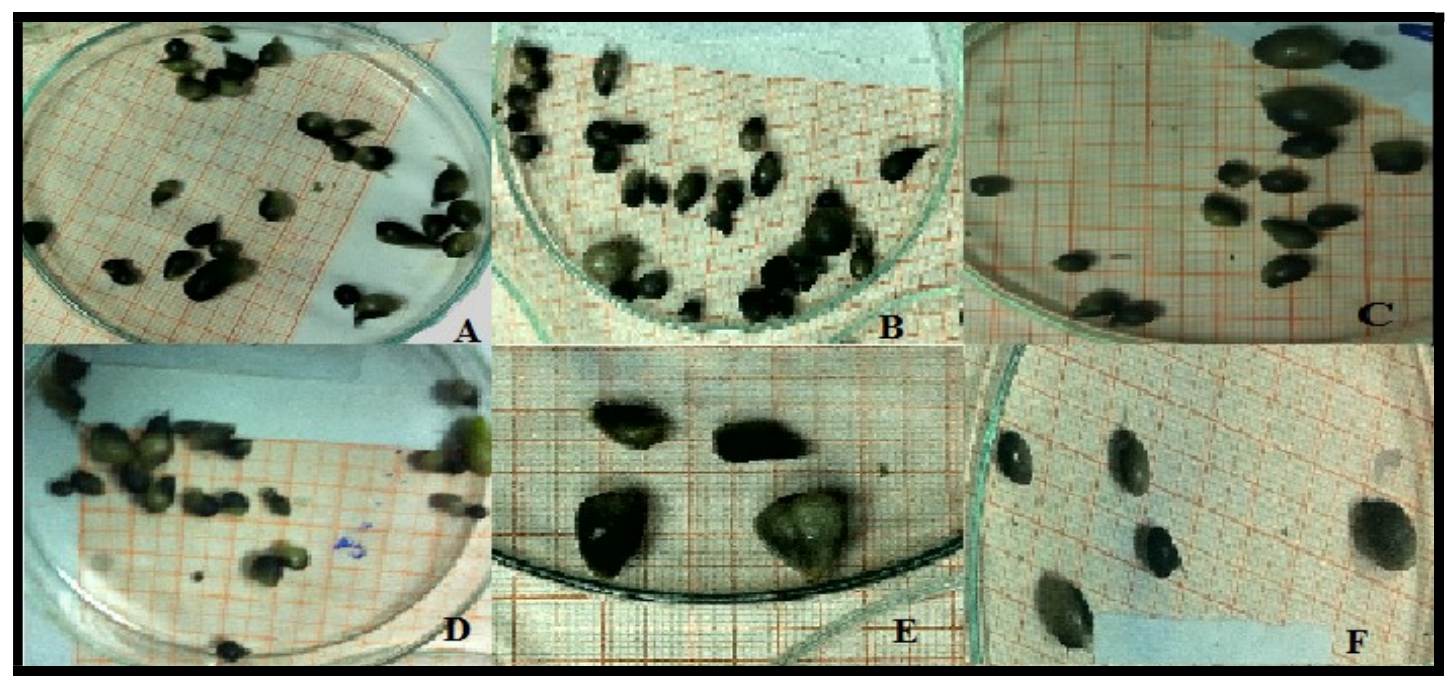

Fig. 3: In vitro bulblets synthetic seeds from T-3 of six garlic landraces; A) Salaqus-3, B) Aswan, C) Borg El-Arab, D) El Behera, E) Sids-40 Ayat and F) Clone-21

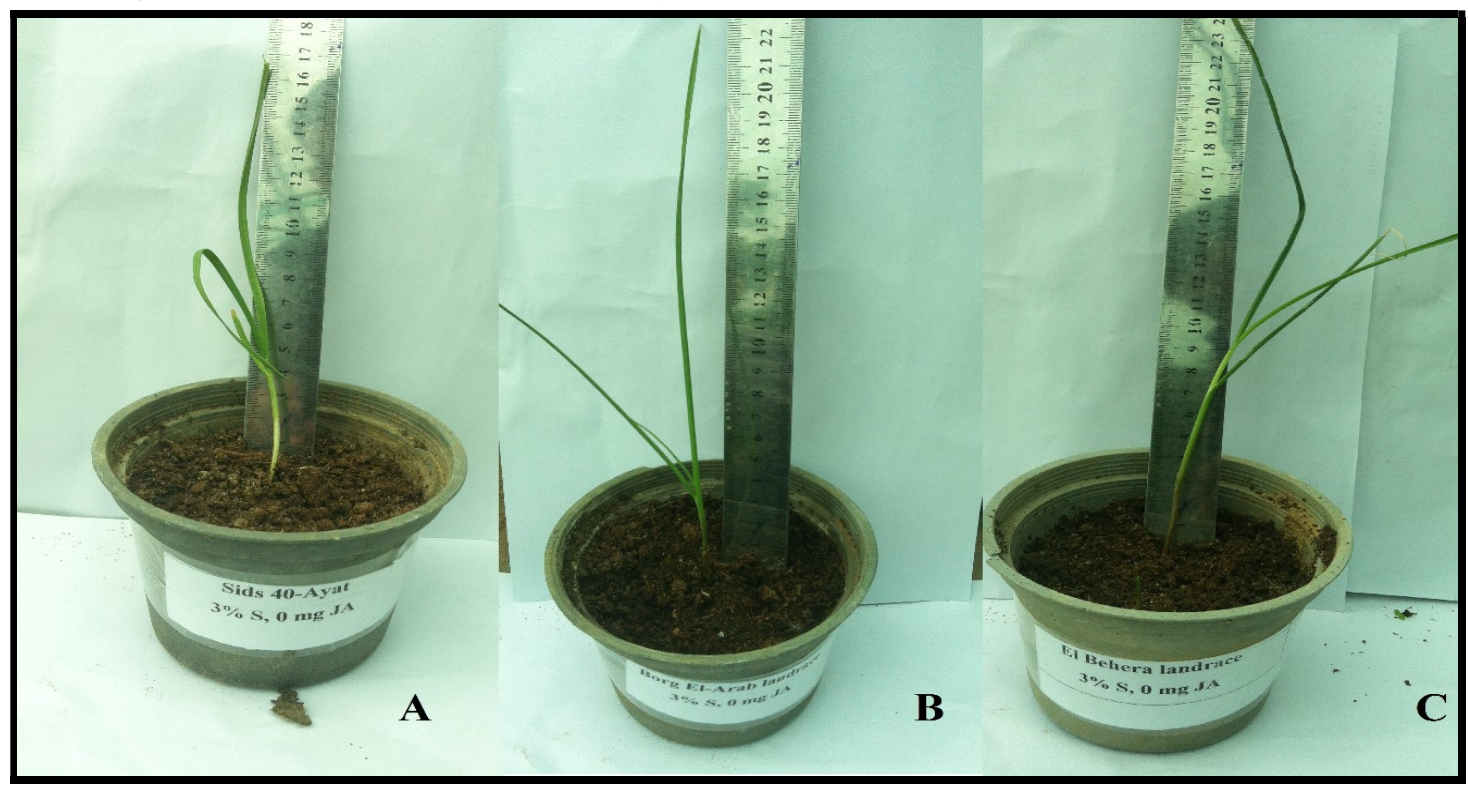

Fig. 4: Synthetic seeds-derived plants from T-1 of Sids- 40 Ayat, Borg El-Araband El Behera landraces grown in peat-moss, sand and soil (1:1:1) mixture and watered with tap water, under greenhouse condition after 3 weeks of sowing. 
Bekheet 2006, Mahajan et al., 2013, Paz-Robeldo and Tovar-soto 2012, Gonapathi et al., 1992 and Kim and Park 2002 who reported the importance of synseeds as an alternative method of garlic micropropagation.

\section{CONCLUSION}

It could be possible to conclude that the local Egyptian garlic landraces showed a great genetic diversity in all characters. This study clarified the promising invitro approach for plant regeneration and bulblets formation, which could be used as alternative propagation method, cultivars rejuvenation and germplasm conversation management along with capsulation technology.

\section{REFERENCES}

Abdel-halim, H. H., 2014. Garlic germplasm resources evaluation and somaclonal mutagenesis technology study based on gamma radiation and EMS treatment on callus. Ph-D thesis. Institute of Vegetables and Flowers, Chinese Academy of Agric. Sci.

Abou El-Magd, M. M., T. El-Shourbagy and S. M. Shehata, 2012. A comparative study on the productivity of four Egyptian garlic cultivars grown under various organic material in comparison to conventional chemical fertilizer. Australian J. of Basic and Applied Sci., 6(3): 415-421.

Abu El-Oyun, D. I., 2010. The performance of some Egyptian garlic strains under Assiut conditions. M. Sc. Thesis, Fac. of Agric., Assiut Univ.

Ahmed, S. I., 2012. Garlic production in calcareous soil as affected by genotypes and population density. J. Plant Production, Mansoura Univ., 3 (6): 957 - 970.

Al-Otayk, S., M. Z. El-Shinawy and M. I. Motawei, 2008. Variation in productive characteristics and diversity assessment of garlic cultivars and lines using DNA markers. Met. Env. Arid Land Agric. Sci., 20(1): 63- 79.

Anwar, E. A. I. G., 2012. Evaluation of some garlic (Allium sativum L.) cultivars grown under Mansoura region conditions. Res. J. of Agric. and Bio. Sci., 8(5): 407-410.

Baghalian, K., S. A. Ziai, M. R. Naghavi and H. N. Badi, 2006. Post-planting evaluation of morphological and allicin content in Iranian garlic (Allium sativum L.) ecotypes. Scientia Horticulturae, 107(4): 405-410.

Bekheet, S. A., 2006. A synthetic seed method through encapsulation of in vitro proliferated bulblets of garlic (Allium sativum L.). Arab J Biotech., 9(3): 415-426.
Conci, V. C., A. Canavelli and P. Lunello, 2003. Yield losses associated with virus-infected garlic plants during five successive years. Plant Disease, 87(12): 1411-1415.

Co-Stat V. 6.303 Copyright (1998-2004). CoHort Software798 Lighthouse Ave. PMB 320, Monterey, CA, 93940, USA.

Dawood, A. R., 2011. A comparative study of growth, yield and storability of some garlic cultivars and clones under Assuit conditions. M. Sc. Thesis, Fac. Agric., Assiut Univ.

Dixit, V., S. P. Rai and B. R. Chaudhary, 2013. Allium sativum: four step approach to efficient micropropagation. Int. J. Innov. Biol. Res., 2(1): 6-14.

F.A.O. 2016. Economic and Social Department: The Statistical Division.

Ganapathi, T. R., P. Suprasanna, V.A Bapat, and P.S Rao, 1992. Propagation of banana through encapsulated shoot tips. Plant Cell Rep., 11: 571-575.

Ghosh, B., and S. Sen, 1994. Plant regeneration from alginate encapsulated somatic embryos of Asparagus cooperi Baker. Plant cell reports, 13(7): 381-385.

Haque, M. S., T. Wada and K. Hattori, 1998. Novel method of rapid micropropagation using cyclic bulblet formation from root tip explants in garlic. Japanese J. Breeding, 48(3): 293-299.

Haque, M. S., T. Wada and K. Hattori, 2003. Shoot regeneration and bulblet formation from shoot and root meristem of garlic cv Bangladesh local. Asian J. Plant Sci., 2(1): 23-27.

Helmy, E. M. S., S. A. AbdAl-Aziz., H. S. AbdelRazzak., M. A. Wahb-Allah and A. AlGarban, 2011. Evaluation of some agronomic traits and genetic relationships among developed garlic clones by RAPD markers and protein analysis. American-Eurasian J. Agric. Environ. Sci., 10: 829-839.

Keller, E.J and A. Senula, 2013. Micropropagation and cryopreservation of garlic (Allium sativum L.). In: Protocols for micropropagation of selected economicallyimportant horticultural plants. Lambardi, M., E. A. Ozudogru, and S. M. Jain (eds.). Springer. New York (US). Ch. 28: 353-368.

Kim, M. A. and J. K. Park, 2002. High frequency plant regeneration of garlic (Allium sativum L.) calli immobilized in calcium alginate gel. Biotech. Bioprocess Eng., 7: 206-211.

Koda, Y., 1997. Possible involvement of jasmonates in various morphogenic events. Physiol. Plant., 100(3): 639-946. 
Kumar Sunil, Pande VP, A. Kumar., 2017. Genetic Variability, Heritability and Genetic Advance in Garlic (Allium sativum L.). Int. J. Pure App. Biosci. 5(3): 849-853.

Lanzotti, V. 2006. A Review the analysis of onion and garlic. J. Chrom., 1112(1): 3-22.

Mahajan, R., K. Sharma., S. Bandryal., P. Jamwal and $\mathrm{P}$. Billowria, 2013. In vitro propagation and cryopreservation of snow mountain garlic endemic to Himalayan region. Int $\mathrm{J} \mathrm{Adv}$ Biotech. Res., 4(3): 372-379.

Metwally, E. M. I. and M. E. El-Denary, 2003. Evaluation of "Avrdc" international garlic collection under Egyptian conditions. ActaHort., 604: 559:564.

Moustafa, Y. M. M., S. S. Latif, G. F. Abd El Naem, H. M. H. Fouly and S.I. Ahmed, 2009. Performance of new imported foreign garlic genotypes grown under the Egyptian conditions. Egypt. J. Agric. Res., 87(1): 219243.

Murashige, T and F. Skoog, 1962. A Revised Medium for Rapid Growth and Bioassays with Tobacco Tissue Cultures. Physiol. Plant., 15(3): 473-497.

Nagakubo, T., A. Nagasawa and H. Ohkawa, 1993. Micropropagation of Garlic Through in vitro bulblet formation. Plant Cell, Tiss. Org. Cult., 32(2): 175-183.

Nagakubo, T., M. Takaichi and K. Oeda, 1997. Micropropagation of Allium sativum L.(garlic). In: High-Tech and Micropropagation V. Springer Berlin Heidelberg. Y.P.S. Bajaj (ed.). 39: 3-19.

Nojiri, H., H.Yamane, H. Seto, 1992. Qualitative and quantitative analysis of endogenous jasmonic acid in bulbing and non-bulbing onion plants. Plant Cell Physiol. 33: 12251231.

Obiadalla, H. A., 2014. Screening of thirteen garlic (Allium sativum L.) genotypes for characteristics of yield and quality under Sohag condition. J. of Agric. Veterinary Sci. Qassim Uni., 7(2): 195-204.
Ravnikar, M., B.Vilhar, N. Gogala, 1992. Stimulatory effect of jasmonic acid on potato stem node and protoplast culture. J. Plant Growth Regul. 11: 29-33.

Ravnikar, M., J. Žel., I. Plaper and A. Špacapan, 1993. Jasmonic acid stimulates shoot and bulb formation of garlic in vitro. J. Plant Growth Regul., 12(2): 73-77.

Robledo-Paz A. and H. M. Tovar-Soto, 2012. Biotechnological Tools for Garlic Propagation and Improvement. In: Innovations in Biotechnology, E. C. Agbo. (ed.). In Tech., Rijeka, Croatia, 474 p.

Saraf R.F, S.M. Kurmvanshi, R.S. Sharma, M. S. Parihar, 2000. Relative performance of garlic (Allium sativum L.) varieties in Vindhyan Plateau of Madhya Pradesh. Crop Research, Hissar. 19(1): 149-151.

Senula, A. and R.J. Keller. (2000). Morphological characterization of garlic core collection and establishment of a virus-free in vitrogene bank. AlliumImprov. Newsl.,10: 3-5.

Sharma, S., A. Shahzad and J. A. Teixeira da Silva, 2013. Synseed technology- A complete synthesis -a review. Biotech. Advances. 31(2): 186-207.

Snedecor G. W and W. G. Cochran, 1980. Statistical methods. $7^{\text {th }}$ edition, Lowa state university press, Ames, Lowa.

Takahashi, K. K. Fnjino, Y. Kikuta, 1995. Involvement of the accumulation of sucrose and the synthesis of cell wall polysaccharides in the expansion of potato cells in response to jasmonic acid. Plant Sci. 111: 11-18.

Vavilov, N. I., 1926. Studies on the origin of cultivated plants. Bull. Appl. Bot., 16: 1-248. C.F.

Vavilov, N. I., 1951. The origin, variation, immunity and breeding of cultivated plants. Chron Bot., 13: 1-364.

Yasseen, Y., W. E. Splittstoesser and R. E. Litz, 1994. In vitro shoot proliferation and production of sets from garlic and shallot. Plant Cell, Tiss. Org. Cult., 36(2): 243-247.

Youssef, N. S. and H. S. H Tony, 2014. Influence of different planting date on the performance of new garlic genotypes grown under El-Minia governorate conditions. Nat Sci., 12(5): 112119. 


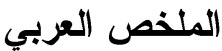

\section{تقييم سلوك نمو بعض سلالات الثوم المصري وانتاج البذور الصناعية من الثوم معليا \\ حجازي حسن حجازي'، جيهان عبد العزيز الثرقاوي'، صلاة النبي سيد احمد' 'أب \\ 'قسم الخضر - كلية الزر اعة - جامعة الاسكندرية \\ كدينة الابحاث العلمية و التطبيقات التكنولوجية}

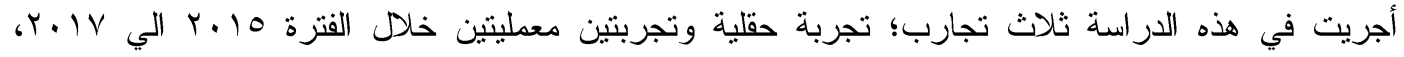

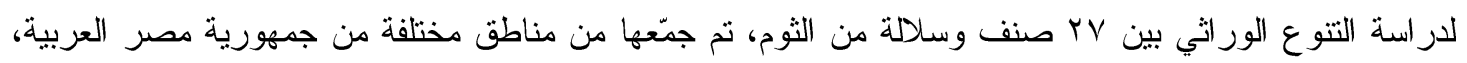
حيث تهدف الدراسة الي التقييم الحقلي و المعملي لسلوك أصناف وسلالات الثوم على المستوى الظاهري، وتنكوين البذور الصناعية بإستخدام البلابل المتكونه معملياً.

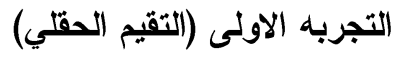

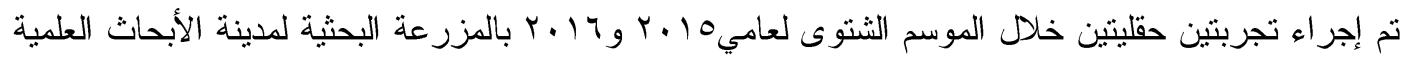
و النطبيقات التكنولوجية- برج العرب- الاسكندرية- مصر ، وذللك بهدف تقييم صفئ صفات النمو الخضري و المحصول الكلي ومو اصفات جودة الابصال للتز اكيب الور اثية من الثوم تحت الدراسة وكذلك تحديد درجة النتابه الور اثى بينها على مستوى الصفات المورفولوجية وذلك بغرض التحسين الوراثي لهذه السلالات المحلية من خلال برنامج نربية لاحق.

وقد تم زر اعة فصوص الثوم للأصناف والسلالات المستخدمة بتصميم القطاعات العشوائيه الكاملة (RCBD)،

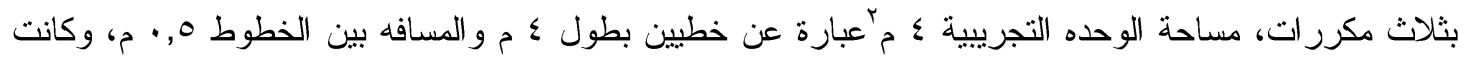

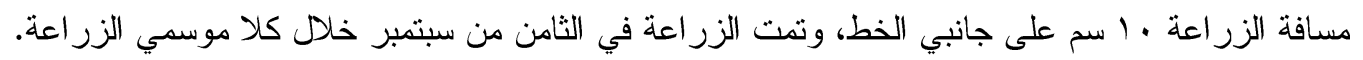
ويمكن تلخيص أهم النتائج فى النقاط التالية: ا. أظهر جدول تحليل التباين وجود إختلافات معنوية بين الأصناف والسلالات المستخدمة في الدراسة في كل الصفات الخضرية و المحصولية المدروسة.

r. تفوقت سلالة Borg El-Arab في صفات النمو الخضري مثل؛ إرتفاع النبات، متوسط عدد الأوراق/نبات، طول و عرض الورقة، الوزن الطازج للنبات و العرش، و كذللك في صفة المحصول الكلي.

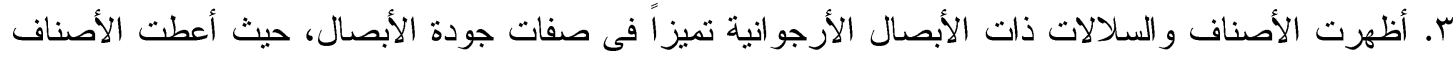

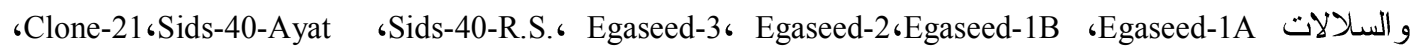
Bany gonamy أقل منوسط عدد فصوص/ Salaqus ،Al Ayat-1 ،Bany gonamy و . أعلى قيمة معنوية لمتوسط وزن الفص وذلك فى الموسم النمو الأول و الثانى على الترتيب.

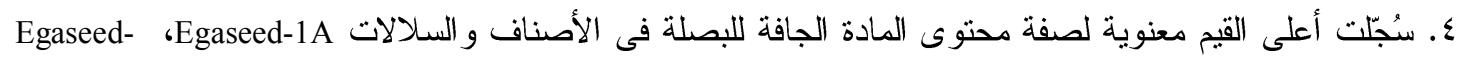

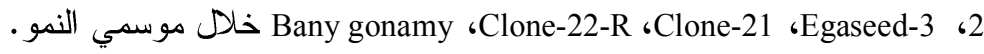
التجربه الثاتية (الإكثار الاقيق و تكوين البصيلات والبذور الصناعية للثوم معملياً) تم إجر اء سلسلة من التجارب المعملية بمعمل زر اعة الأنسجة بقسم الخضر - كلية الزر اعة- جامعة الإسكندرية،

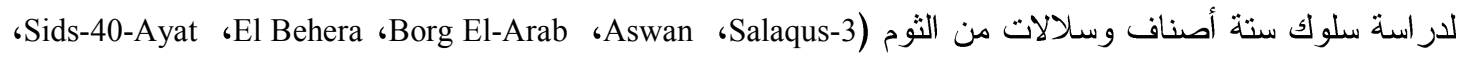


(Clone-21 لإنتاج السيقان الخضرية و البصيلات معطلياً بإستخدام بيئة (1962) Murashge \& Skooge المضاف إليها

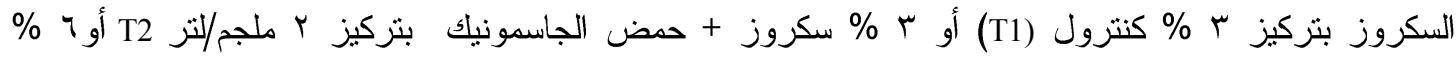
سكروز + حمض الجاسمونيك بتركيز r ملجم/لتر (T3). تم إجراء تجربة لإنتاج بذور الثوم الصناعية معملياً، حيث تم تغليف البصيلات الناتجة من زر اعات بـات الأنسجة

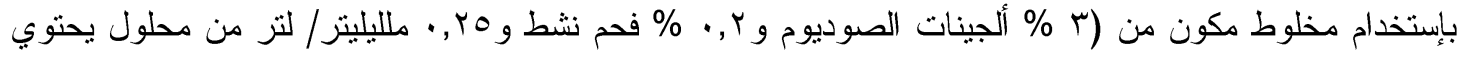
علي مضاد حيوي) ولتصلب الغلاف الصناعي للبصيلة نم وضعها بمحلول ب, r \% كلوريد كالسيوم على المقلب المغناطيسي لمدة •ـ دقيقة. أجريت تجربة لنتبيت البذور الصناعية في الصوب البلاستيكية بزر اعتها في مخلوط

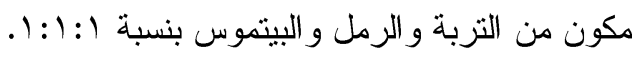
تم إجر اء التجارب كتجارب عاملية ذات عاملين (ستة تر اكيب وراثية و ثناثل بئيات غذائية مختلفة المحتوى)

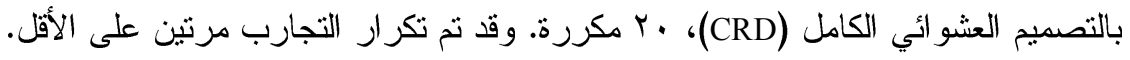
ويمكن تلخيص النتائج فى النقاط التالية: 1. أظهرت النتائج وجود إختلافات معنوية فيما يتعلق بقدرة الأصناف والسلالات المستخدمة على إعادة النمو

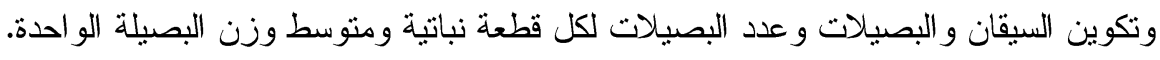

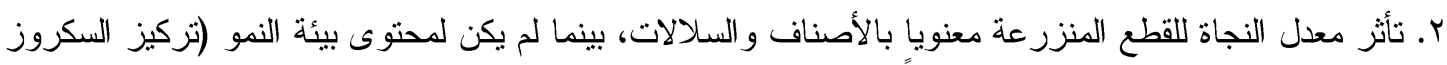
وحمض الجاسمونيك) تاثير اً معنوياً لمعدل النجاة. r. أعطت السلالاتين Borg El-Arab و Salaqus-3 أكبر عدد من السيقان الخضرية لكل قطعة منزرعة و أكبر عدد

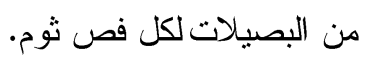
ع. أدت زيادة نركيز السكروز فى بيئة النمو و إضافة حمض الجاسمونيك إلى زيادة في تكوين بصيلات الثوم

$$
\text { للأصناف و السلالات تحت الدر اسة. }
$$

0. أعطت معاملة-r (بيئة MS المزودة ب ؟ \% سكروز و r ملجم/لتر حمض الجاسمونيك) أعلى متوسط معنوي

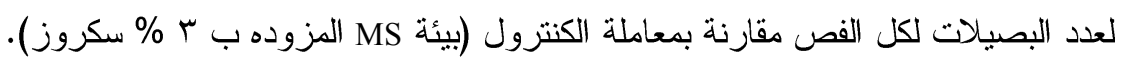

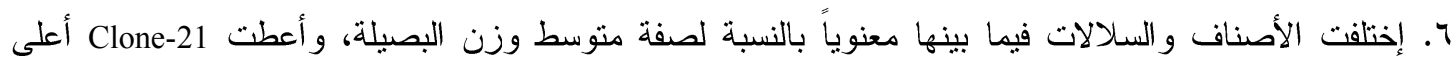

$$
\text { متوسط لوزن البصيلة. }
$$

V. أعطت معاملة الكنترول (بيئة MS المزوده ب r \% سكروز) أعلى متوسط معنوى لوزن البصيله مقارنة

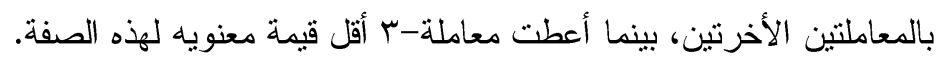

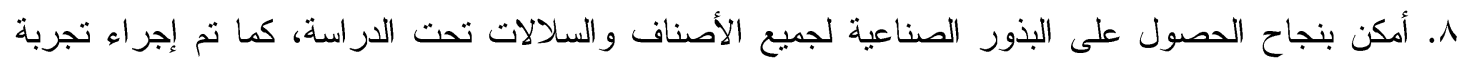
إنبات بنجاح تحت ظروف الصوب البلاستيكية حيث أنبتت البذور الصناعية للثوم (البصيلات الناتجه معملياً

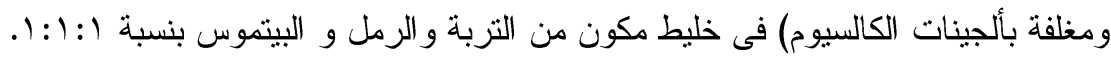

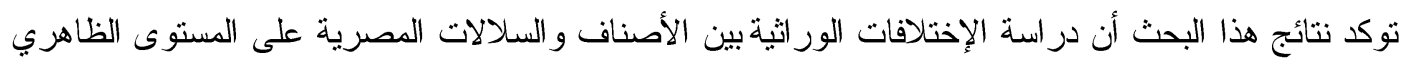

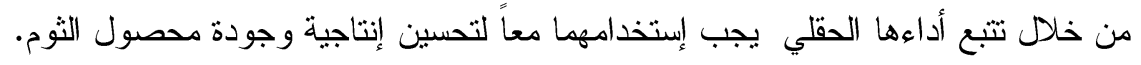

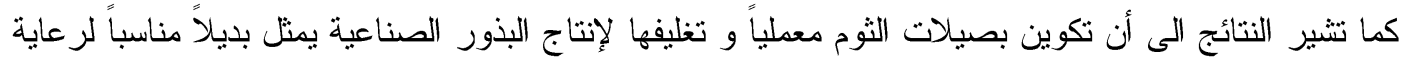

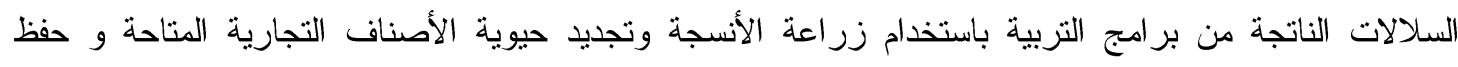

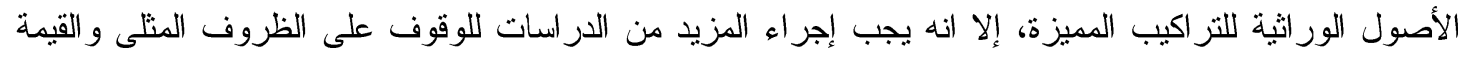

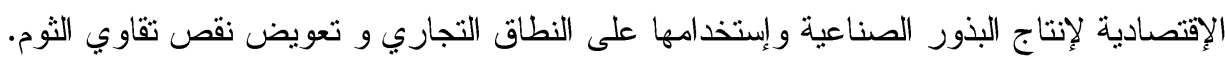

